DOI: $10.20472 / B M .2015 .3 .3 .001$

\title{
WHAT DO BUSINESS MANAGERS VALUE WHEN THEY NEGOTIATE? EMPIRICAL EVIDENCE FROM THE ARABIAN GULF
}

\section{ALEXANDRE BACHKIROV}

\begin{abstract}
:
Social psychological outcomes subjectively valued by Middle Eastern Arab business negotiators were explored through a qualitative interview-based study. Participants included 15 business managers from various organizations in the Muscat metropolitan area of Oman for whom negotiation constitutes an essential part of the job. The semi-structured format of the interviews ensured consistency and flexibility in the data collection. Analysis of the narratives showed that the subjective value structure includes the following components: balance and moderation, concern for the negotiation outcomes of the counterpart, the motivation to create a win-win situation, honesty, patience, trust and trustworthiness. Managerial implications for the practice of cross-cultural negotiations are discussed.
\end{abstract}

\section{Keywords:}

negotiation, social psychological outcomes, subjective value, honesty, patience, trust

JEL Classification: M16

\section{Authors:}

ALEXANDRE BACHKIROV, Sultan Qaboos University, Oman, Email: alexbach@squ.edu.om

\section{Citation:}

ALEXANDRE BACHKIROV (2015). What do business managers value when they negotiate? Empirical evidence from the Arabian Gulf. International Journal of Business and Management, Vol. III(3), pp. 1-11., 10.20472/BM.2015.3.3.001 


\section{Introduction}

This exploratory investigation developed into a separate study during a larger scale study on business negotiation in the Arabian Gulf. In the process of the originally designed project, a research need emerged to explore the issue of social psychological outcomes of Middle Eastern Arab business negotiators. Together with economic outcomes - terms and conditions of the settlement, division of resources, creation and distribution of value - social psychological outcomes, which produce subjective value, constitute important factors in negotiation dynamics. According to Thompson (1990), social psychological outcomes are interpretative in nature and concerned with a negotiator's perceptions of (1) the negotiation situation, (2) the counterpart and (3) oneself. A fourth element was later suggested by Curhan, Elfenbei and Xu (2006), denoted as feelings about the final terms of the deal. While a body of work exists identifying what Westerners value when they negotiate (Curhan et al., 2006; Curhan, Elfenbei and Eisenkraft, 2010; Novemsky and Schweitzer, 2004), no systematic empirical attempts have been made to investigate the issue of subjective value in negotiation beyond Western contexts in general and in the Arabian Middle East in particular. Redressing this situation is the purpose of the present study.

Understanding what social psychological outcomes are valued and expected by one's negotiation counterpart adds an extra tool to the set of negotiator competencies. From this perspective, the insights into the components of subjective value for negotiators native to the Arabian Middle East creates a competitive advantage for those desirous of sustainable business in that region. One strategic area of global significance is known as the Gulf Cooperation Council (GCC) and includes Bahrain, Kuwait, Oman, Qatar, Saudi Arabia and the United Arab Emirates. Due to its rapid development, the GCC region is highly attractive to a range of international companies, particularly in such industries as oil and gas, telecommunications and civil engineering. To illustrate, the Plan Abu-Dhabi 2030 comprises multiple infrastructure projects worth more than US $\$ 400$ billion (Davidson, 2009) and has stimulated fierce international competition for contracts. However, because of significant cultural distance (Shenkar, 2001), industrial marketers from outside the Arabian Gulf may find themselves at a disadvantage due to their lack of knowledge about the subjective value structure of local negotiators. The need to understand what Middle Eastern Arab business managers value when they negotiate constituted a compelling reason for this study. The present investigation was carried out in Oman, which can be taken as a typical representative of the GCC countries (Moideenkutty and Schmidt, 2011). Oman is an affluent, oil-rich, modern society which strategically follows a course toward economic growth and development while carefully protecting its cultural heritage and belief system (Peterson, 2004). 


\section{Theory}

Negotiation as a field of research has been stimulating academic thought for several decades (Bazerman, Curhan, Moore and Valley, 2000; Carnevale and Pruitt, 1992; Thompson, Wang and Gunia, 2010). Recently, cross-cultural negotiation has emerged as a distinct domain of research (Adair et al., 2004; Brett, 2000; Metcalf et al., 2007). A notable limitation of the existing work, however, is that it is rooted in Western values and assumptions (Brett and Gelfand, 2006). The issue of social psychological outcomes of negotiation may be particularly sensitive to the influence of national cultural values, which motivated the present investigation.

The influential study of Curhan et al. (2006) drew scholarly attention to the fact that it is reductionist and overly simplistic to view negotiation only as "an economically motivated or strategic interaction best practiced by rational, unemotional actors" (p. 493). True, economic outcomes denote the quality of negotiation performance. However, social psychological outcomes (i.e. the attitudes and perceptions of negotiators) are in themselves increasingly viewed as significant aspects valued by negotiators (Thompson, 1990). In addition, empirical evidence suggests that perceptual, attitudinal and social psychological factors play important roles in predicting the economic outcomes of negotiations (Bazerman et al., 2000; Curhan et al., 2010). In other words, a positive emotional experience, not only positive economic results, can influence objective outcomes in future negotiations. This is achieved when one succeeds in increasing the counterpart's subjective value, thus creating the basis for a positive and fruitful business relationship in the future.

To understand the nature and consequences of the social psychological dimension of negotiation, the construct of the negotiator's subjective value has been introduced. Defined as the "social, perceptual, and emotional consequences of a negotiation" (Curhan et al., 2006: 494), it encompasses four factors: instrumental subjective value (feelings about distributional fairness and outcome satisfaction), process subjective value (feelings about the fairness of treatment and the efficiency of the process), self subjective value (feelings about being competent vs. loosing face) and relationship subjective value (trust, impressions, foundation for future relationships). Originally, in a study with 103 participants (students, community members and negotiation practitioners), 20 specific subjective value categories were identified that were associated with different levels of personal importance and frequency of reporting. The categories included non-quantifiable terms of the agreement, quantifiable terms of the agreement, legitimacy, impact on an outside party, respect, fairness/equity, good attitude, positive emotion, effective process, morality/ethics/religious, resolution, relationship quality, trust, listening, satisfaction, acknowledgement of wrongdoing/remedy, saving face, compromise/mutual agreement, winning and 
peaceful/non-confrontational. Table 1 offers a summary of the five most important and the five least important categories for business negotiations arranged in rank order of importance to the respondents in Curhan et al.'s (2006) study.

Table 1. What do business negotiators value?

\begin{tabular}{lllll}
\hline \hline Category & Importance & \multicolumn{2}{l}{ Frequency } \\
\cline { 2 - 4 } & Ranking & $M$ & $S D$ & $\%$ \\
\hline
\end{tabular}

Five most important categories of subjective value

\begin{tabular}{lllll}
\hline Morality / ethics & 1 & 6.7 & 0.7 & 2.1 \\
\hline Acknowledgement of wrong doing / remedy & 2 & 6.6 & 0.5 & 1.1 \\
\hline Trust & 3 & 6.3 & 0.4 & 1.7 \\
\hline Resolution & 4 & 6.2 & 0.8 & 1.9 \\
\hline Fairness/equity & 5 & 5.9 & 1.6 & 3.6 \\
\hline
\end{tabular}

Five least important categories of subjective value

\begin{tabular}{lllll}
\hline Impact on an outside party & 10 & 5.3 & 1.4 & 7.6 \\
\hline Compromise / mutual agreement & 11 & 5.3 & 1.5 & 0.6 \\
\hline Respect & 12 & 5.2 & 2.0 & 6.1 \\
\hline Effective process & 13 & 4.8 & 1.4 & 2.3 \\
\hline Saving face & 14 & 3.3 & 2.2 & 0.8 \\
\hline \hline
\end{tabular}

Notes:

1. Importance of categories was measured on a scale ranging from 1 (not very important) to 7 (extremely important).

2. No participants identified "peaceful/non-confrontational" as a category having subjective value.

Why research social psychological outcomes and subjective value derived from negotiators' feelings about themselves, about the counterpart and about the negotiation process? Empirical evidence suggests several reasons. First, given the interactional nature of negotiation, maintaining and enhancing the quality of the relationship between the parties may intrinsically be a self-defined goal beyond economic issues in bargaining (Gelfand, Smith, Raver and Nishii, 2006). In addition, such positive feelings as confidence, satisfaction and connection with others can be regarded as utility in themselves (Curhan et al., 2010). Also, it is often challenging to ascertain how well or how poorly one has performed in a negotiation encounter. Given the lack of direct information, subjective value derived from bargaining will guide the negotiator's intuitive evaluation of the objective outcomes (Curhan et al., 2006). Finally, subjective value can act in the capacity of an antecedent to future objective value through the perception of reputation, good will and interpersonal rapport (Tinsley, O'Connor and Sullivan, 2002). Importantly, subjective value has a long-lasting impact (Thompson et al., 2010). 


\section{Context}

The study was conducted in Oman, located in the Arabian Peninsula. Over the past several decades, the country has experienced a dynamic period of economic development and prosperity (Peterson, 2004) transforming the country from an isolationist nation into a progressive monarchy seeking to become a global economic player (Aycan Al-Hamadi, Davis and Budhwar, 2007). The effects of globalization are evident in the presence of multinational corporations and exposure of local employees to international management practices. At the same time, being firmly embedded in traditional Middle Eastern culture, organizational life in Oman is influenced by the Islamic work ethic and tribal codes of loyalty and honor (Ali, 1992; Robertson, Al-Khatib, Al-Habib and Lanoue, 2001). A distinctive characteristic of organizational culture is "sheikhocracy", a strong top-down authoritative structure based on personal autocracy and indubitable respect for those who make the rules (Kassem and Habib, 1989). However, while authoritarianism is applied to "out-groups", the emphasis is on consultation with "in-groups" (Common, 2008). Within Western cultural research paradigms, Oman is regarded as a high power distance, high uncertainty avoidance and collectivistic society (Moideenkutty, Al-Lamki and Murthy, 2011).

\section{Method}

This study employed an approach based on qualitative methodology. Data were collected using semi-structured interviews which facilitated flexibility and consistency in the process of data collection. Planning, preparation and conducting of interviews were a partial credit requirement for a university course. As a part of the course project, students interviewed managers whose role entails negotiations as an essential component of their job. All interviewers were given an interview guide to assist in leading the discussion. The interview guide focused on such topic areas as competitive and collaborative negotiation, concession making, power and influence, communication and trust and relationship building.

One methodological limitation of earlier research (Curhan et al., 2006) was the reliance on self-reports (i.e. the participants were asked to identify their own subjective value factors). As Curhan et al. (2006) acknowledged, the critical question is whether respondents indeed value what they say they value in negotiation. To overcome this problem in the present study, the negotiators' subjective value was elicited indirectly. The respondents were asked to give advice to the interviewers as future business negotiators. The researcher anticipated that in a semi-structured discussion the interviewees would project their subjective value recognisable through the themes meaningful to them. The central methodological assumption was that the advice of 
experienced negotiation practitioners would necessarily be based on their own subjective value structure.

To ensure openness of the interviewees and their willingness to cooperate, anonymity and confidentiality in participation were emphasised. Most of the interviews were digitally recorded with interviewees' consent. In-depth notes were taken in a few cases when respondents were reluctant to have the interview recorded. Fifteen interviews were conducted. The interviews were transcribed verbatim and closely examined for salient topics. This study reports on the emerged themes related to social psychological outcomes valued by Omani business negotiators.

\section{Findings}

During the analysis of the interview data, in addition to generic negotiation competencies such as listening and communication skills, planning skills and the ability to use negotiation power, the following thematic categories and subcategories emerged as important subjective values: balance and moderation, concern for the negotiation outcomes of the counterpart, the motivation to create a win-win situation, honesty, patience, trust and trustworthiness.

Interviewed managers recognised the importance of factual knowledge concerning issues related to negotiations and the importance of preparation. However, they emphasised that this knowledge should be used in a balanced and well-adjusted manner. As one manager explained:

You must always be prepared and do your homework about customers and clients. Before going to the meeting, do some background checks on them, about their budget, how much they are willing to spend, so that you know what type of people they are or what type of organization they represent. Don't be very lenient or soft. On the other hand, don't be stiff and rigid.

(Publication and advertising manager)

Another noteworthy way in which knowledge about the counterpart's needs, preferences and priorities should be used can be termed "concern for the negotiation outcomes of the other". One manager shared the following view reflecting this principle:

... be ready with full information, solutions and suggestions. ... [yet] be patient, empathic, try to negotiate in a way that you do not harm the other side, show that you like them and you want them to be a part of success and tell them about their good aspects.

(Head of purchasing) 
Similarly, two other negotiators emphasised that:

The most important advice that I can give you is to think about others as much as you think about yourself. Do not let others lose while you are making profits.

(Contract analyst)

Don't always look for your company benefit only and forget the negotiator on the other side. Always put yourself in his position.

(Company owner)

The attitude of being concerned for the negotiation outcome of the other was further complemented by a stronger view regarding the importance of not hurting the counterpart's negotiation outcome:

Try to maximise both party outcomes if possible. In addition, try not to harm the other side's outcome or [at least] minimise the harm. Be sure that you have the ability to build relationships with the other side and try to build your relationship through trust and truth. Be patient to follow the negotiation process and try not to jump quickly through the negotiation process.

(Finance manager)

As the previous quotation suggests, the underlying motivation for not hurting the counterpart's negotiation outcomes is linked to the intention to create a win-win negotiation situation. Strategically, it is viewed as a foundation for a long-term business relationship. As one negotiator elaborated:

And try to make the win-win situation your top priority ... So you don't go there and, basically, run for your self-interest and you just try to fight for your own sake. You need to have a look into the other's needs also (the other party) because, as I mentioned before during the interview, if you don't have honesty and integrity, you will not assure yourself a longer relationship with that person and this might have even more consequences in the future. ... Always seek a win-win situation because it will assure you a long-run/long-term business relationship.

(Senior sales manager)

Interestingly, pursuing a win-win approach was the most important guidance the interviewed managers could give to would-be negotiators. One respondent distilled this idea into the following statement:

The only advice I can give you is that you should always use the win-win principle in all of your future negotiations.

(Consultant and expert on the tender board) 
The notion of concern for the counterpart's negotiation outcome by creating a win-win situation emerged as closely related to the value of trust and trustworthiness. As one interviewee said:

Be confident, know the subject that you are going to be negotiating, understand your partner on the other side, and keep in mind it needs to be to a win-win situation. If you always win and the other person loses, the other person will have a bad image of you; it's important for you to become trustworthy.

(General manager)

Intrinsically, trustworthiness is rooted in honesty. One company owner urged:

Be honest and clear with yourself first and then with others. Cheating or lying is doing no good. ... Try to be patient because you will encounter different types of people and characteristics. Deal with people as your ethics compels you to behave regardless of the other side's ethics.

(Company owner)

A detrimental consequence of being dishonest is lost business. One negotiator explained:

I advise you, as a future business negotiator, to be honest, trustworthy and fair. Honesty, truthfulness and fairness are the real capital of any negotiator. You may pretend to be more intelligent than others and gain a big deal but if the others discover you have been dishonest, unfair and untrue, you will lose forever. (Import manager)

The above results demonstrate that the factors from which Middle Eastern Arab negotiators accrue subjective value primarily encompass balance and moderation, concern for the negotiation outcomes of the other party, the motivation to create a winwin situation, honesty, patience, trust and trustworthiness.

\section{Discussion and Conclusions}

The purpose of this study was to explore what social psychological outcomes are expected by Middle Eastern Arab negotiators. The underlying methodological assumption was that, by articulating practical advice to aspiring business managers, negotiation practitioners would be projecting their own subjective value. The emerged pattern of elements of subjective value differs noticeably from those describing negotiators in the study conducted in the USA by Curhan et al. (2006). For instance, the respondents in the present study referred to the importance of having a moderate and balanced stance during negotiation (i.e. being neither too lenient nor too rigid). This element of subjective value was not found in the subjective value structure of Western negotiators. Three other elements - concern for the outcomes of the counterpart, the 
motivation to create a win-win situation and patience - also emerged as having subjective value for Middle Eastern Arab negotiators. Conceptually, these elements might be remotely related to the saving face, respect and peaceful / non-confrontational aspects of Western respondents. However, the statistics suggest the low importance of saving face and respect for North American negotiators (see Table 1) while peaceful / non-confrontational did not emerge within their subjective value structure at all. The above differences in the subjective value structure can be attributed to the cultural dissimilarity in the collectivistic versus individualistic value orientations of the participants. Honesty and fairness (morality/ethics) and trust are present in the subjective value structure of negotiators from both cultures.

Certain limitations need to be acknowledged. The methodology relied on narrative accounts of a relatively small number of practicing negotiators. Making generalisations was beyond the scope of this research. However, follow-up investigations should aim to collect data from a larger number of negotiation practitioners to create an opportunity for additional themes related to negotiator subjective value to emerge.

The findings reported in this study have important managerial implications. For example, negotiation practitioners involved in cross-cultural and international negotiation, should consider potential differences in expectations of their counterparts from overseas. If, for example, in addition to economic outcomes, maintaining and enhancing the relationship with the other party is of strategic importance, then it is essential to ensure that the business partners draw subjective value from their negotiation experience. Thus, knowing what creates subjective value for the other party becomes a vital tool for negotiation success. This study contributes to our understanding of cross-cultural differences in negotiators' subjective value. 


\section{References}

Adair, W., Brett, J., Lempereur, A., Okumura, T., Shikhirev, P., Tinsley, C. and Lytle, A., 2004. Culture and negotiation strategy. Negotiation Journal, 20(1), pp.87-111.

Ali, A.J. 1992. The Islamic work ethic in Arabia. The Journal of Psychology, 126(5), pp.507-19.

Aycan, Z., Al-Hamadi, A.B., Davis, A. and Budhwar, P. 2007. Cultural orientations and preferences for HRM policies and practices: the case of Oman. The International Journal of Human Resource Management, 18(1), pp.11-32.

Bazerman, M.H., Curhan, J.R., Moore, D.A. and Valley, K.L., 2000. Negotiation. Annual Review of Psychology, 51, pp.279-314.

Brett, J.M. (2000). Culture and negotiation. International Journal of Psychology, 35(2), pp.97-104.

Brett, J.M. and Gelfand, M.J., 2006. A cultural analysis of the underlying assumptions of negotiation theory. In: L. Thompson, ed. 2006. Negotiation theory and research. New York: Psychology Press. pp.173-201.

Carnevale, P.J. and Pruitt, D.G., 1992. Negotiation and mediation. Annual Review of Psychology, 43, pp.531-82.

Common, R. 2008. Administrative change in the Gulf: Modernization in Bahrain and Oman. International Review of Administrative Sciences, 74(2), pp.177-93.

Curhan, J.R., Elfenbein, H.A. and Eisenkraft, N. 2010. The Objective Value of Subjective Value: A Multi-Round Negotiation Study. Journal of Applied Social Psychology, 40(3), pp.690-709.

Curhan, J.R., Elfenbein, H.A. and Xu, H. 2006. What do people value when they negotiate? Mapping thedomain of subjective value in negotiation. Journal of personality and social psychology, 91(3), pp.493-512

Davidson, C., 2009. Abu Dhabi's new economy: Oil, investment and domestic development. Middle East Policy, 16(2), pp.59-79.

Gelfand, M.J., Major, V.S., Raver, J.L., Nishii, L.H. and O'Brien, K. 2006. Negotiating relationally: The dynamics of the relational self in negotiations. Academy of Management Review, 31(2), pp.427-51.

Kassem, M.S. and Habib, G.M. 1989. Strategic management of services in the Arab Gulf states: Company and industry cases. New York: Walter de Gruyter.

Metcalf, L.E., Bird, A., Peterson, M.F., Shankarmahesh, M. and Lituchy, T.R., 2007. Cultural influences in negotiations: A four country comparative analysis. International Journal of Cross Cultural Management, 7(2), pp.147-68.

Moideenkutty, U., Al-Lamki, A. and Sree Rama Murthy, Y. 2011. HRM practices and organizational performance in Oman. Personnel Review, 40(2), pp.239-51.

Moideenkutty, U. and Schmidt, S.M. 2011. Leadership tactics: enabling quality social exchange and organizational citizenship behavior. Organization Management Journal, 8(4), pp.229-41.

Novemsky, N. and Schweitzer, M.E. 2004. What makes negotiators happy? The differential effects of internal and external social comparisons on negotiator satisfaction. Organizational Behavior and Human Decision Processes, 95(2), pp.186-97.

Peterson, J.E. 2004. Oman: Three and a half decades of change and development. Middle East Policy, 11, pp.125-37.

Robertson, C.J., Al-Khatib, J.A., Al-Habib, M. and Lanoue, D. 2001. Beliefs about work in the Middle East and the convergence versus divergence of values. Journal of World Business, 36(3), pp.223-44. 
Shenkar, O., 2001. Cultural distance revisited: Towards a more rigorous conceptualization and measurement of cultural differences. Journal of International Business Studies, 32(3), pp.519-35.

Thompson, L.L., 1990. Negotiation behavior and outcomes: Empirical evidence and theoretical issues. Psychological Bulletin, 108, pp.515-32.

Thompson, L.L., Wang, J. and Gunia, B.C. 2010. Negotiation. Annual Review of Psychology, 61, pp.491515.

Tinsley, C.H., O'Connor, K.M. and Sullivan, B.A. 2002. Tough guys finish last: The perils of a distributive reputation. Organizational Behavior and Human Decision Processes, 88(2), pp.621-42. 